\title{
Research Paper: The Role of Self-efficacy in the Relationship Between Classroom Climate and Students' Educational Motivation
}

\author{
Najme Sadat Haji Vosoogh ${ }^{1} \mathbb{C}$, Jahanshir Tavakolizadeh ${ }^{1^{*}}$ (D), Majid Pakdaman ${ }^{1} \mathbb{C}$ \\ 1. Department of Psychology, Faculty of Sciences, Qaenat Branch, Islamic Azad University, Qaenat, Iran.
}

\begin{tabular}{|c|c|}
\hline $\begin{array}{l}\text { suevourdedicict toscan } \\
\text { and read the article online }\end{array}$ & Citation Haji Vosoogh NS, Tavakolizadeh J, Pakdaman P. The Role of Self-efficacy in the Relationship Between Classroom \\
\hline 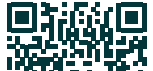 & $\begin{array}{l}\text { Climate and Students' Educational Motivation. Journal of Research \& Health. 2021; 11(4):225-234. http://dx.doi.org/10.32598/ } \\
\text { JRH.11.4.1839.1 }\end{array}$ \\
\hline 茴 & doli : http://dx.doi.org/10.32598/JRH.11.4.1839.1 \\
\hline
\end{tabular}

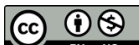

Article info:

Received: 08 Sep 2020

Accepted: 11 Oct 2020

Publish: 01 Aug 2021

\section{Keywords:}

Educational motivation, Classroom climate, Selfefficacy

\section{ABSTRACT}

Background: "Motivation" is an influential factor in the learning process, which its absence can prevent the learner from learning. Motivation affects both new learning and performance, skills, strategies, and pre-learned behaviors. "Educational motivation" is an essential aspect of education and the learning process. Educational motivation is generally referred to as the desires, needs, and factors that cause a person to have hope and resilience in educational environments for the flow of education and obtain the necessary results from it and transactional satisfaction. The purpose of this research was to determine the role of self-efficacy in the relationship between classroom climate and students' educational motivation.

Methods: This correlational research was done on 250 people selected by a simple multi-stage random sampling method from male and female high school students of Gonabad in 20192020. The measurement tools were Sinclair \& McInroy Educational Motivation Scale (SIMS), Psychosocial Climate Inventory by Fraser, Giddings, and Mac Ruby (1955), The Morgan-Jinks Student Efficacy Scale (MJSES). Multiple regression was used to analyze the findings.

Results: The results showed a significant relationship between classroom climate and educational motivation without the presence of self-efficacy $(r=0.41)$, while there was no significant relationship between these two variables with the presence of self-efficacy $(\mathrm{r}=0.186)$. The findings also indicated that the classroom climate perception was a significant predictor of mediated academic motivation without self-efficiency $(\mathrm{P}=0.0346)$.

Conclusion: There was a significant relationship between classroom climate and educational motivation without the presence of self-efficacy and classroom climate perception was not an effective predictor of educational motivation with the presence of self-efficacy. Hence, it is recommended to focus on factors predicting educational motivation in future studies.

\footnotetext{
* Corresponding Author:

Jahanshir Tavakolizadeh, PhD.

Address: Department of Psychology, Faculty of Sciences Qaenat Branch, Islamic Azad University, Qaenat, Iran.

Phone: +98 (915) 5332069

E-mail:drtavakolizadehj@gmail.com
} 


\section{Introduction}

owadays, the need for achievement is one of the initial motivations studied $\mathbf{N}$ in detail [1]. Butel believes that educational motivation is the all-out tendency to evaluate self-performance considering the highest standards to strive for success in performance and enjoy the joy that is accompanied by performance success. Students have different levels of educational motivation and behave in completely different ways in their lives. For example, at a high level of the need for achievement, people are more likely to pursue higher education, higher grades, and extracurricular activities than those who need a low level of need for achievement [2].

Educational psychologists and scholars have studied many variables to identify the predictors of educational performance and sought to identify the most essential and significant components in this field to specify educational quality and performance improvement by studying the variables related to educational achievement. In other words, the main reasons for paying attention to motivation in education have been mentioned due to their effective relationship with new learning, skills, strategies, behaviors, and educational achievement [3].

One of the factors affecting self-efficacy and consequently, educational motivation is the classroom environment and climate, which plays a vital and robust role in the educational and psychological performance of students and the interaction between them [4]. The school environment is one of the most critical places in students' lives because they spend a lot of time at school [5]. The psychological climate of the learning environment (classroom) has significant effects on students' learning behaviors, their target orientation, their beliefs, educational and social motivation, emotional performance, educational values, and educational achievement [5].

The classroom and school environment, the school administrative system, and the teacher education method have undeniable effects on educational performance and cognitive and self-efficacy processes [6]. School or classroom activities perception is a wide range of processes, attitudes, and beliefs, including perceptions of control, support for autonomy, choice, and enjoyment [7]. As a small and subsidiary community, the classroom is made up of different people who are different in terms of experiences, culture, and personality. These people bring their characteristics into the classroom and prevail in a different climate. Therefore, the creators of the class- room climate are teachers and students whose primary goal is education and learning [8]. Therefore, a favorable climate in the classrooms is necessary for teaching and learning. A favorable and appropriate climate is a positive and purposeful relationship between the teacher and students in the classroom with "efficiency" [9]. Therefore, recognizing the classroom climate and interacting with peers can provide valuable feedback for teachers because this factor affects dropout, absenteeism, sadness and depression, anxiety, student resistance to the teacher, lack of camaraderie between students in the classroom, dissatisfaction, and lack of interest in lessons and learning. Various factors affect the way students learn and perform in the educational environment, among which two factors related to the characteristics of the classroom climate and individual characteristics of students (such as the level of motivation and arousal to acquire knowledge, cognitive and metacognitive strategies, and personality) are more critical. The interaction of these two factors plays a vital role in increasing the educational environment's quality and efficiency, which increases a person's learning and education [10].

Some studies have indicated the relationship between high levels of educational self-efficacy and variables, such as adjustment and success in school and asking others for help in educational issues. They believe that selfefficacy is correlated with effective learning strategies, self-regulation, educational performance, and social interaction skills with classmates [11]. According to studies, the relationship between a happy classroom climate and educational motivation can promote appropriate individual and social upbringing and reduce educational and job burnout. A positive and significant relationship between classroom climate and educational motivation has been reported [12-19].

Educational self-efficacy is positively and significantly related to educational motivation, and classroom climate and psychosocial relationships of peers and teachers have a broad effect on self-efficacy and motivational processes [20]. Teacher and student support, especially peers, positively and significantly affect students' educational selfefficacy [21]. There is a positive and significant relationship between self-efficacy and educational motivation [22-26]. Several studies have been conducted in this field in Iran. For example, a study reported that self-efficacy has an influential role in educational performance and motivation [27]. Another study showed that competition in the psychosocial climate of the classroom could significantly be a negative predictor of educational self-efficacy. 
Moreover, friction and discipline of the psychosocial climate significantly and positively predicted educational self-efficacy. The discipline of the psychosocial climate significantly and positively predicted the context of students' educational self-efficacy dimension, while discipline in the psychosocial climate of the classroom negatively predicted the effort in the educational self-efficacy [28].

"Self-efficacy" is another crucial factor considered by educational psychologists regarding improving performance and increasing students' motivation levels. Previous studies have indicated a direct and indirect relationship (mediating) between self-efficacy and educational motivation, which means more positive students' beliefs about their ability to do educational affairs leads to better educational motivation and performance. Thus, selfefficacy is a strong determinant and predictor of the level of achievement in students [29-32].

In the recent decade, "self-efficacy" has been one of the most substantial positive factors of motivation, which has attracted many psychologists parallel with the development of positive psychology. Self-efficacy is so closely and effectively correlated to motivation and some consider self-efficacy as a dimension of intrinsic motivation. Self-efficacy and motivation are two sides of the same coin. In other words, as soon as people believe in their abilities and capabilities, they have a double motivation to continue and accomplish their tasks and goals [33, 34].

"Educational self-efficacy" is sometimes considered as one of the main concepts related to self-efficacy, which refers to students' beliefs about the ability to do a certain amount of duties [5]. The psycho-mental nature is critical in defining and understanding self-efficacy. Self-efficacy does not only mean judging and calculating the objective and external results of their capabilities and volume but it also means the individuals' perceptual level and motivation. For example, it refers to a person who has significant achievements and is endorsed by others but does not consider himself self-sufficient and worthy in terms of believable differences, perceptual perspectives, and unrealistic existential expectations. Regarding the self-efficacy as a mediating variable, it can be said that a sense of trust, confidence, and firm confidence in being able to overcome as a mediator of this relationship becomes necessary and essential despite any factor related to students' educational motivation (including context, facilities, level of instructors, etc.) [33].

Previous studies have focused on the mentioned variables and the importance of the role of the classroom climate as an environmental variable and educational motivation as an often internal variable in student education and the need for self-efficacy in various areas of education and mental health. Given that there are no studies in the country on the simultaneous relationship between the three studied variables (classroom climate, self-efficacy, and educational motivation), the purpose of this research was to investigate the role of self-efficacy in the relationship between classroom climate and students' educational motivation.

\section{Methods}

This correlational research employed a regression method. The statistical population of the research included all high school students (3057 cases) of Gonabad in 2019-2020 (1646 female and 1411 male). Multi-stage random sampling in this research was performed. The sample size was estimated to be 200 students, which increased to 250 people to reduce the sampling error and the ability to generalize the results to the entire statistical population. In the first stage, 6 schools, including 3 female and 3 male schools, were randomly selected out of 25 male and female high schools in Gonabad. In the second stage, the researcher referred to the schools and selected several classes in each school, and in the next stage, the samples were randomly selected in each classroom based on the list of students. The inclusion criteria were being a high school student, willingness to participate in research for 12 to 15 years, and the lack of a history of mental disorders, and the exclusion criteria were withdrawal from the study for any reason, being absent in one of the stages of the research, and no complete answer to the questionnaires.

The measurement tools of the research included the Sinclair \& McInroy Educational Motivation Scale, Psychosocial Climate Inventory by Fraser et al. (1955), and the Morgan-Jinks Student Efficacy Scale (MJSES), which was developed and validated by Fraser et al. (1955). The scale has 20 items with a minimum and maximum score of 20 and 60, which measures the psychological and social climate of the subject. The Iranian form of this questionnaire has been standardized in a sample of middle school students. In this study, the reliability coefficient with Cronbach's alpha for the whole scale and subscales of friction, cohesion, discipline, and competition was reported to be $0.87,0.81,0.79,0.79$, and 0.80 , respectively. In this research, the reliability coefficient was 0.69 with a retest method and tested on 56 students with a threeweek interval $[34,35]$.

The main form of the Educational Motivation Scale was created by Sinclair \& McInroy (1992) with 100 terms. The 
short 49-item form was compiled by Bahrani in Shiraz. The internal stability of this form is equal to 0.77 for the whole questionnaire and ranges from 0.27 to 0.77 for the dimension of the tendency to achievement and dimension of external motivation, respectively with a median of 0.50 and a reliability coefficient of 0.95 obtained through the retest method. This value was relatively high and ranged from 0.70 (dimension of the tendency to achievement) to 0.90 (dimension of external motivation) for its 11 dimensions. Its median coefficient was 0.77 [35].

The Morgan-Jinks Student Efficacy Scale (MJSES) was developed by Morgan et al. (1999). This scale has 30 questions and three subscales of talent, effort, and context. The items of the scale are rated on a four-point Likert scale. The scale has an internal consistency of 0.82 obtained using Cronbach's alpha method. Cronbach's alpha coefficient of three subscales of talent, effort, and context were reported to be $0.78,0.66$, and 0.70 , respectively. The validity of this scale in Iran has been reported as favorable through factor analysis and its reliability coefficients for overall self-efficacy, and its dimensions of talent, effort, and context are 0.76, 0.66, 0.65, and 0.60, respectively with Cronbach's alpha method [36, 37].

Table 1 shows the values of Cronbach's alpha coefficient to check the reliability of all three questionnaires. According to the results and the reliability values, the good reliability of the research questionnaires is confirmed, considering all its values more than 0.7. Motivation questionnaire questions had the highest reliability with the alpha and mental climate values of 0.85 and 0.81 , respectively. The MJSES had the lowest reliability value with the alpha and self-efficacy values of 0.69 and 0.74 , respectively.

Initially, the researcher received a letter of introduction from the University Vice-Chancellor for Education to conduct the study. Sampling was performed after obtaining the necessary permissions and coordination. The researcher referred to the selected schools, and the subjects completed the mentioned questionnaires. The necessary explanations were provided about the research purpose and the subjects were informed about the information confidentiality and providing right answers to the questions of the questionnaires before completing the questionnaires. It should be noted that written and informed consent was obtained from the students before the study. SPSS v. 22 statistical software was used to analyze the data, and the results were reported using descriptive and inferential statistics.

\section{Results}

The statistical population of the study was 3057 people, including 1646 females and 1411 males. The sample size is estimated as many as 250 people. According to Table 2, out of 250 participants, 127 cases $(50.8 \%)$ were female and 123 cases $(49.2 \%)$ were male. Also, 76 cases $(30.4 \%)$ were in the eighth grade, $75(30 \%)$ in the ninth grade, and $99(39.6 \%)$ were in the tenth grade. A total of 62 people (24.8\%) were studying humanities, 54 people $(21.6 \%)$ mathematics, 72 people $(28.8 \%)$ experimental sciences, 41 people (16.4\%) professional technical, and $21(8.4 \%)$ were studying work and knowledge. The average age of the subjects was 15 years. The relevant assumptions for using this inferential statistic were first confirmed before performing the regression model (for example, the independence and normality of the residuals).

The regression model was used to evaluate the predictability of the studied indicators for educational motivation, in which the educational motivation index was included as a dependent variable, and the classroom climate was entered as an independent variable. Finally, this regression was fitted with and without the presence of self-efficacy in the model. The significance of the model was first checked for each regression model. If the model was significant, the $\mathrm{R}^{2}$ index was used as the value of the motivation index.

We examined the predictive role of classroom climate with the presence of self-efficacy and according to Table 3, a P-value of 0.0346 was obtained, which was not significant, showing the unpredictability of the classroom climate in the presence of self-efficacy for educational motivation. Moreover, the regression model result showed that the perception of the classroom climate was a significant predictor of educational motivation without a mediating role $(\mathrm{P}=0.421)$.

The correlation coefficient was used to determine the relationship between the studied indicators and educational motivation. This coefficient was calculated with and without the self-efficacy in the model. The Pearson correlation coefficient was used in the model without the presence of self-efficacy, and the marginal correlation coefficient was used in the model with the presence of self-efficacy to control the effect of self-efficacy.

As shown in Table 4, a positive and significant relationship was found between classroom climate and educational motivation without self-efficacy $(r=0.415)$, while the obtained correlation coefficient between these two variables mediated by self-efficacy $(\mathrm{r}=0.186)$ was not significant. The percentage of variance explaining the 
Table 1. Cronbach's alpha values of the research questionnaires used

\begin{tabular}{ccc}
\hline Self-efficacy & Psychological Climate & Motivation \\
\hline $74 \%$ & $81 \%$ & $85 \%$ \\
\hline
\end{tabular}

URA

presence or absence of self-efficacy in the model was expressed using the $\mathrm{R}^{2}$ index. The percentage of variance explained by the whole mediated model was equal to 0.201 according to the $\mathrm{R}^{2}$ index. A good classroom climate can positively affect self-efficacy and motivation; thus, the lack of a proper classroom climate can negatively affect these indicators (Table 5).

\section{Discussion}

The purpose of this research was to determine the role of self-efficacy in the relationship between classroom climate and students' educational motivation. According to the findings, consistent with several studies, the classroom climate had a positive and significant with educational motivation [38]. The classroom is a small and subsidiary community with different people who have similarities and differences in terms of experiences, culture, personality, and other factors and need a favorable climate in the classroom for teaching, learning, and being motivated in this direction. Students are motivated to do their homework and advance their educational interests together and receive the necessary guidance to improve educational performance in their relationships with educators and teachers. These improvements increase self-confidence and self-esteem and cause motivation more than before [39].

"Competition" is one of the dimensions of classroom climate, which has a positive and significant relationship with student's educational achievement and motivation [22]. In other words, there are many interactions between students at school and in the classroom, of which competition between students is a situation, in which students fight each other in a friendly way to achieve a goal. Competitive activities are motivating, exciting, and enjoyable, which allow students to demonstrate competencies and abilities by comparing themselves with others and their previous performance. In addition, the competition improves performance by affecting the attempt to impress the people to achieve a goal. This improvement increases educational achievement. Iranian schools today are highly affected by competitive education. Many techniques and strategies used in schools, like score and rank and the first and second grade in the scoring system, encourage competition [40].

Table 2. Demographic information of the subjects

\begin{tabular}{ccc}
\hline Variables & Category & No. (\%) \\
\hline Gender & Female & $127(50.8)$ \\
& Male & $123(49.2)$ \\
\hline Level of education & Eighth grade & $76(30.4)$ \\
& Ninth grade & $75(30.0)$ \\
& Tenth grade & $99(39.6)$ \\
& Humanities & $62(24.8)$ \\
Educational field & Math & $54(21.6)$ \\
& Experimental sciences & $72(28.8)$ \\
& Technical and professional & $41(16.4)$ \\
\hline Age $(y)$ & Work and knowledge & $21(8.4)$ \\
\hline
\end{tabular}


Table 3. Predicting role of the classroom climate for educational motivation

\begin{tabular}{|c|c|c|c|c|}
\hline Models & & Sum of Squares & $\mathbf{F}$ & Significance \\
\hline \multirow{3}{*}{$\begin{array}{l}\text { Psychological climate without the } \\
\text { mediating role of self-efficacy }\end{array}$} & Regression & 6.16 & 17.1 & 0.0346 \\
\hline & Residual & 0.81 & & \\
\hline & Total & 7.372 & & \\
\hline \multirow{3}{*}{$\begin{array}{l}\text { Psychological climate with the mediat- } \\
\text { ing role of self-efficacy }\end{array}$} & Regression & 1.211 & 7.860 & 0.4210 \\
\hline & Residual & 7.154 & & \\
\hline & Total & 7.372 & & \\
\hline
\end{tabular}

uRA

"Discipline" is another dimension of the classroom climate. In justifying its positive and significant relationship with educational motivation, it can be said that discipline refers to the extent, to which students do the homework assigned by their teacher regularly and on time. Discipline is considered a positive factor because it is used by the teacher for educational achievements considering the importance of students' independence. If the discipline provides conditions for optimal management of the classroom climate and meets the obligations and expectations to provide effective training, it can be effective in educational motivation. Furthermore, "frictional" relationships negatively and significantly reduce students' educational motivation, and on the contrary, friendly and intimate relationships and a sense of belonging and support effectively increase students' motivation [41-44].

In the present study, classroom climate was not significantly related to self-efficacy in educational motivation and could not play an indirect predictive role for self-efficacy. Our findings are also consistent with some of the studies in this field. According to some reports [45, 46], in the last three decades, the psychosocial climate of the classroom can sometimes not predict self-efficacy and educational motivation. In explaining and analyzing this lack of relationship and predicting the classroom climate for students' educational motivation, it can be expressed that discipline or upbringing generally have a weak relationship with educational achievement and improvement in students' attitudes. Some students are inattentive and weak to their peers, classmates, teachers, and the school environment, despite being motivated and performing well in lessons and learning [47] or they gradually take an individualistic approach, do not care about interpersonal and collective relationships, and strongly think about spending school hours and being successful in passing grades and doing homework [48].

In some cases, the classroom climate and the derived indicators from its context and culture may be relatively different and contradictory by students' perceptions and selected methods for the development and improvement of students' performance and personality, beliefs, and future career-educational perspectives. In this situation, it is normal for inappropriate classroom climate styles, such as observant or controller styles, to have a negative effect on students' motivation, especially self-efficacy.

\section{Conclusion}

Our results confirmed a positive and significant correlation between "perception of psychosocial climate in the classroom" and "students' educational motivation;" however, the classroom climate regarding its predic-

Table 4. Relationship between classroom climate and educational motivation

\begin{tabular}{ccc}
\hline \multicolumn{1}{c}{ Models } & & Classroom Climate \\
\hline $\begin{array}{c}\text { Correlation coefficient without the mediat- } \\
\text { ing role of self-efficacy }\end{array}$ & Pearson correlation coefficient & 0.415 \\
$\begin{array}{c}\text { Correlation coefficient with the mediating } \\
\text { role of self-efficacy }\end{array}$ & Significance & 0.004 \\
& Marginal correlation coefficient & 0.186 \\
\end{tabular}


Table 5. The variance of classroom climate explained the educational motivation

\begin{tabular}{ccccc}
\hline Models & $\mathbf{R}$ & $\mathbf{R}^{\mathbf{2}}$ & Adjusted $\mathbf{R}^{\mathbf{2}}$ & Estimated Standard Deviation \\
\hline $\begin{array}{c}\text { Psychological climate without the mediat- } \\
\text { ing role of self-efficacy }\end{array}$ & $0.405^{\mathrm{a}}$ & 0.164 & 0.025 & 0.58505 \\
$\begin{array}{c}\text { Psychological climate with the mediating } \\
\text { role of self-efficacy }\end{array}$ & $0.615^{\mathrm{a}}$ & 0.354 & 0.201 & 0.47653 \\
\hline
\end{tabular}

a: The percentage of variance explaining the presence or absence of self-efficacy in the model was expressed us ing the $\mathrm{R}^{2}$ index; the percentage of variance explained by the whole mediated model was equal to 0.201 according to the $R^{2}$ index.

tive role for educational motivation did not have the necessary power and significance in the present study. Because the classroom climate is linked to the relationship between the student with his/her classmates and teachers, this relationship may not be sincere. Therefore, the lack of a significant relationship in this study can indicate the lack of this relationship in students. There was a significant relationship between the perception of classroom climate and educational motivation without the mediating role of self-efficacy, while there was no significant correlation between these two variables with the mediating role of self-efficacy. However, the perception of classroom climate was not an effective predictor of educational motivation with or without the mediating role of self-efficacy. It is recommended to focus on other factors predicting educational motivation in future studies.

\section{Recommendations}

Considering the predictive role of classroom climate on the educational motivation (directly and indirectly with self-efficacy) and the relationship between them, the insiders, teachers, and educators are recommended to provide the necessary solutions for the appropriate classroom climate for education and training to increase motivation and improve students' educational achievement. For example, teachers should not teach using the traditional method to a group of students and should create opportunities for the learner to be actively involved in improving educational content and social interaction. Students must be taught to be self-disciplined and to take an active role in their learning by targeting, monitoring, and evaluating achievement and going beyond future needs by discovering interests. These students must also adopt important factors and necessary training as effective measures considering the role of self-efficacy in this regard (the effect of class climate on increasing the educational motivation).

Given that the present research was conducted on students in Gonabad, the researchers suggested repeating this research in other areas with different cultures and other age groups and courses. Such studies increase the generalizability of the findings and provide a basis for comparing the findings. Considering the insignificant relationship between classroom climate and educational motivation by mediating self-efficacy, it is recommended to examine the role of other factors involved in educational motivation.

\section{Research Limitations}

This research had some limitations that should be considered in future studies. One of the main problems and limitations was the lack of access to students due to the E-learning system due to the outbreak of the COVID-19 in the country.

\section{Ethical Considerations}

\section{Compliance with ethical guidelines}

This study was approved by the Ethics Committee of the University of Gonabad (Code: 09 /24/2/129).

\section{Funding}

This research did not receive any grant from funding agencies in the public, commercial, or non-profit sectors.

\section{Authors' contributions}

Methodology and investigation: All authors; Writing review \& editing and writing - original draft, data analysis: Najmeh Sadat Haji Vosough.

\section{Conflict of interest}

The authors declared no conflict of interest.

\section{Acknowledgments}

The authors would like to express their appreciation to all girls and boys in high schools of Gonabad and all the people who helped in this research. 


\section{References}

[1] Macklem GL. Practitioner's guide to emotion regulation in school-aged children. Berlin/Heidelberg: Springer Science \& Business Media; 2008. https://psycnet.apa.org/record/2007-13789-000

[2] Atkinson JW. Motivational determinants of risk-taking behavior. Psychol Rev. 1957; 64(6, Pt.1):359-72. [PMID] [DOI:10.1016/j.sbspro.2010.03.340]

[3] Ghamari M. [The relationship between social capital and internal motivation with academic achievement among high school students of Karaj (Persian)]. J Instr Eval. 2013; 6(22):45-58. http://jinev.iaut.ac.ir/article_521538_0.html?lang=en

[4] Bacanli F. Career search self-efficacy expectation scale: Validaty and reliability studies. Educ Science: Theory and Practice. 2006; 6(2):318-30. https://www.proquest.com/ openview / cc9ff401784b09539c4351d130ec02a3/1?pqorigsite $=$ gscholar\&cbl $=28575$

[5] Altunsoy S, Cimen O, Ekici G, Atick AD, Gokgman A. An assessment of the factors that influence biology teacher candidates, levels of academic self-efficacy. Procedia Soc Behav Sci. 2010; 2(2):2377-82. [DOI:10.1016/j.sbspro.2010.03.340]

[6] Carroll A, Houghton S, Wood R, Unsworth K, Hattie J, Gordon L, et al. Self-efficacy and academic achievement in Australian high school students: The mediating effects of academic aspirations and delinquency. J Adolesc. 2009; 32(4):797-817. [PMID] [DOI:10.1016/j.sbspro.2010.03.340]

[7] Larose S, Bernier A. Social support processes: Mediators of attachment state of mind and adjustment in late adolescence. Attach Hum Dev. 2010; 3(1):96-120. [PMID] [DOI:10.1080/14616730010024762]

[8] Dorman J. Classroom environment research: Progress and possibilities. Queensland J Educ Res. 2002; 18(2):112-40. http://www.iier.org.au/qjer/qjer18/dorman.html

[9] Ames C. Classrooms: Goals, structure and student motivation. J Educ Psycholy. 1992; 84(3):261-71. [DOI:10.1080/14616730010024762]

[10] Houshmand Neghabi Z, Morshedian Rafiee S. Mediating effect of academic engage meutin relationship between academic self- efficacy and academic achievement among adolescence in Tehran. Life Sci J. 2013; 10(5s):393-9. http:/ / www.lifesciencesite.com/lsj/life1005s/071_17288life1005s_393_399.pdf

[11] Gota AA. Effects of parental styles, academic self - efficacy and achievement motivation on the academic achievement of university student in Ethiopia [PhD. dissertation]. Perth Edith Cowan University. https://ro.ecu.edu.au/theses/461/

[12] Nelson JR, Stage S, Trout A, Duppong-Hurley K, Epstein $\mathrm{MH}$. Which risk factors predict the basic reading skills of children at risk for emotion and behavioral disorders? Behav Disord. 2019; 33(2):75-86. [DOI:10.1016/j.sbspro.2010.03.340]

[13] Corkin DM, Shirley LY, Wolters CA, Wiesner M. The role of the college classroom climate on academic procrastination. Learn individ Differ. 2014; 32:294-303. [DOI:10.1016/j. sbspro.2010.03.340]

[14] Dorman JP. Associations between classroom environment and academic efficacy. Learning Environ Res. 2001;4(3):243-57. https://link.springer.com/article/10.1023/A:1014490922622
[15] Dorman JP. Association between psychosocial environment and outcomes in technology: Rich classroom in Australian secondary schools. Res Educ. 2009; 82(1):69-84. [DOI:10.1016/j.sbspro.2010.03.340]

[16] Haertel GD, Walberg HJ, Haertel EH. Socia-psychological environments and learning: A quantitative synthesis. Br Educ Res J. 1981; 7(1):27-36. [DOI:10.1016/j.sbspro.2010.03.340]

[17] Haj Shamsayi M, Kareshki H, Amine Yazdi SA. [Testing the model of mediator role of self-regulation in relation between Classroom socio-mental climate and maladjustment (Persian)]. J Sch Psychol Inst. 2014; 3(3):21-37. http://jsp.uma. ac.ir/article_229_3.html?lang=en

[18] Hejazi E, Naghsh Z. [Structural model of the relationship between perception of classroom, goals achievement, self-efficacy, and self- regulation in mathematics (Persian)]. Adv Cogn Sci. 2009; 10(4):27-38. http://icssjournal.ir/article-1-465-en. $\mathrm{html}$

[19] Rajabi G, Chahardolie H, Attari Y. [The relationship of Family Family Functions and Psychosocial atmosphere of the classroom with maladjustment among the high school female and male students in Malayer (Persian)]. J Edu Psychol. 2007; 14(1-2):113-28. https://www.sid.ir/en/journal/ViewPaper. aspx?ID=212201

[20] Bong M. Academic motivation in self-efficacy, task value, achievement goal orientations, and attributional beliefs. JEduc Res. 2004; 97(6):287-98. [DOI:10.1016/j.sbspro.2010.03.340]

[21] Wentzel KR, Caldwell K. Friendships, peer acceptance, and group membership: Relations to academic achievement in middle school. Child Development. 1997; 68(6):1198-209. [DOI:10.1016/j.sbspro.2010.03.340]

[22] Lundberg CA, McIntire DD, Creasman CT. Sources of social support and self-efficacy for adult students. J Coll Couns. 2008; 11(1):58-72. [DOI:10.1002/j.2161-1882.2008.tb00024.x]

[23] Sivrikaya AH. The relationship between academic motivation and academic achievement of the students. Asian J Educ. 2019; 5(2):309-15. https://files.eric.ed.gov/fulltext/ EJ1216482.pdf

[24] Nota L, Ferrari L, Solberg VS, Soresi S. Career search self-efficacy, family support, and career indecision with Italian youth. J Career Assess. 2007; 15(2):181-93 [DOI:10.1002/j.2161-1882.2008.tb00024.x]

[25] Can S. The effects of science student teachers' academic achievements, their grade levels, gender and type of education they are exposed to on their 4mat learning styles (Case of Muğla University, Turkey). Procedia: Social and Behavioral Sciences. 2009; 1(1):1853-7. [DOI:10.1016/j.sbspro.2009.01.327]

[26] Lee EH, Oh HJ. Relationship between motivation and proficiency improvement. Linguistic Res. 2011; 28(2):405-30. http://isli.khu.ac.kr/journal/content/data/28_2/9.pdf

[27] Seidsalehi M, Yonesi J. [Explaining role of academic selfefficacy on academic performance and academic motivation based on social support, academic self-concept, and personality traits: Structural equation modeling (Persian)]. Res Sch Virtual Learn. 2015; 3(9):7-20. http://etl.journals.pnu.ac.ir/ article_1960.html?lang=en 
[28] Khajeh L, Hosseinchari M. [Investigating the relationship between social anxiety and psychosocial atmosphere of the classroom with academic self-efficacy in middle school students (Persian)]. Q J Educ Psychol. 2011; 7(20):131-53. https://www.sid.ir/en/journal/ViewPaper.aspx?ID=252328

[29] Pajares F, Schunk DH. Self and self-belif in psychology and education: An historical perspective. In: Aronson J, editor. Improving Academic Achievement impact of psychological factors on education. New York: Academic Perss; 2002. [DOI:10.1007/s12144-005-1027-4]

[30] Bandura A, Locke EA. Negative Self-efficacy and goal revisited. J Applied Psychol. 88(1):87-99. [DOI:10.1037/00219010.88.1.87]

[31] Schunk DH. Self-efficacy and academic motivation. Educ Psychol. 1991; 26(3-4):207-31. [DOI:10.1080/00461520.1991.9 653133]

[32] Seligman ME, Steen TA, Park N, Peterson C. Positive psychology progress: Empirical validation of interventions. Am Psychol. 2005; 60(5):410-21. [PMID] [DOI:10.1016/j.sbspro.2010.03.340]

[33] Liem AD, Lau S, Nie Y. The role of self-efficacy, task value, and achievement goals in predicting learning strategies, task disengagement, peer relationship, and achievement outcome. Contemp Educ Psychol. 2008; 33(4):486-512. [DOI:10.1016/j.sbspro.2010.03.340]

[34] Greene BA, Miller RB, Crowson HM, Duke BL, Akey KL. Predicting high school students' cognitive engagement and achievement: Contributions of classroom perceptions and motivation. Contemp Educ Psychol. 2004; 29(4):462-82. [DOI:10.1016/j.cedpsych.2004.01.006]

[35] Hosseinchari M, Khayyer M. Classroom psychosocial climate as a component of school culture. J Psychol Achiev. 2002; 9(2):25-43. https://psychac.scu.ac.ir/article_16479. html?lang=en

[36] Rasouli R, Davarzani H. The study of internal and external factors affecting the failure of financial supervision system of sports organizations in Tehran. Sci J Organ Behav Manage Sport Stud. 2014; 1(3):113-9. http:// fmss.journals.pnu.ac.ir/ article_1379.html?lang=en

[37] Karshki H, Kharazi AN, Ghazi Tabatabai SM. [The title of the study of the relationship between school environmental perceptions and achievement goals; Does the type of school, field of study and area of residence make a difference? (Persian)]. J Educ Psychol Stud. 2008; 9(2):79-93. https://www. sid.ir/fa/journal/ViewPaper.aspx?id=96936

[38] Fredricks JA, Blumenfeld PC, Paris AH. School engagement: Potential of the concept, state of the evidence. Rev Educ Res. 2004; 74(1):59-109. [DOI:10.1002/j.2161-1882.2008. tb00024.x]

[39] Goodenow C, Grady KE. The relationship of school belonging and friends values to academic motivation among urban adolescent student. J Exp Educ. 2010; 62(1):60-71. [DOI:10.1002/j.2161-1882.2008.tb00024.x]

[40] Schwartz JP, Buboltz WC. The relationship between attachment to parents and psychological separation in college students. J Coll Stud Dev. 2004; 45(5):556-77. [DOI:10.1002/j.2161-1882.2008.tb00024.x]
[41] Vitaro F. Linkages between early childhood. School success and high school complection. Encyclopedia on Early Childhood Development. 2005; 1-8. http://citeseerx.ist.psu.edu/viewdoc/ download?doi=10.1.1.515.3103\&rep=rep1\&type=pdf

[42] O'Conner E, McCartney K. Attachment and cognitive skill: An investigation of mediating mechanism. J Appl Dev Psychol. 2007; 28(5-6):458-76. [DOI:10.1002/j.2161-1882.2008.tb00024.x]

[43] Hinsz VB. The influence of social aspects of competition in goal- setting situations. Curr Psychol. 2005; 24:258-73. [DOI:10.1007/s12144-005-1027-4]

[44] Friedel JM, Cortina KS, Turner JC, Midgley C. Achievement goals, efficacy belief and coping strategies in mathematics: The role of perceived parent and teacher goal emphases. Contemp Educ Psychol. 2007; 32(3):434-58. [DOI:10.1007/ s12144-005-1027-4]

[45] Fraser BJ. Research on classroom and school climate. In: Gabel D, National Science Teachers Association, editors. Handbook of research on science teaching and learning. Stuttgart: Macmillan; 1994. pp. 493-542. https://www.google. com/books/edition/Handbook_of_Research_on_Science_ Teaching/-sDaAAAAMAAJ?hl=en

[46] Fraser BJ, Sinclair B. Assessing and changing classroom environment in urban middle schools in Texas. Paper presentation at: Annual Conference of the Australian Association for Research in Education. 2-6 December 2001; Fremantle, Australia. https://www.aare.edu.au/publications/aareconference-papers/show/3078/assessing-and-changingclassroom-environments-in-urban-middle-schools-in-texas

[47] Glasgow KL, Dornbusch SM, Troyer L, Steinberg L, Ritter PL. Parental styles, adolescents attribution, and educational outcomes in nine heterogeneous high schools. Child Dev. 1997; 68(3):507-29. [DOI:10.1007/s12144-005-1027-4]

[48] Goodwin I. The relevance of attachment theory to the philisophy, organization, and practice of adult mental health care. Clin Psychol Rev. 2003; 23(1):35-56. [DOI:10.1007/ s12144-005-1027-4] 
This Page Intentionally Left Blank 